\title{
Mercados y estaciones de transporte como focos infecciosos de COVID-19
}

REV EXP MED

\section{Mercados y estaciones de transporte como focos infecciosos de COVID-19}

\author{
Sebastian Iglesias-Osores 1,a, Johnny L Saavedra-Camacho 1,a, Lizbeth M Córdova-Rojas 2,a \\ Sr. Editor:
}

La pandemia de COVID-19 se originó en un mercado en Wuhan en China. Es causada por el nuevo coronavirus (SARS-CoV-2) y se transmite por vía aerógena ${ }^{(1)}$. Cuando las personas se encuentran en el período de incubación o muestran síntomas, se produce la transmisión de COVID-19 de persona a persona y algunas personas permanecen asintomáticas sin dejar de ser infecciosas. Se cree que la transmisión ocurre a través del contacto con superficies infectadas (piel a piel, contacto con objetos inanimados infectados) y luego a través de la boca, nariz u ojos que median la infección por COVID-19. La transmisión también puede ser por inhalación de virus exhalados de gotitas respiratorias y de persona a persona (2).

Se conoce que el estar en ambientes con aglomeraciones aumenta el riesgo de contagio de las personas sanas ${ }^{(1)}$, también se ha visto que las personas que asisten o viven más cerca de los mercados son más propensos a infectarse antes ${ }^{(3)}$. Los gobiernos del mundo han implementado varias medidas de distanciamiento social, las cuales van desde la separación de un metro de distancia entre las personas, cuarentena y el cierre de locales, exceptuando los mercados y las estaciones de transporte masivo. Todas estas medidas se dieron para controlar la rápida transmisión del virus evitando aglomeraciones de personas en lugares clave. El objetivo de esta carta es plantear algunas soluciones para evitar la propagación del virus en los mercados y estaciones de transporte público

Se ha recopilado información del Centro Nacional de Epidemiología, Prevención y Control de Enfermedades (CDC), a través de la Dirección de Redes Integradas en Lima y direcciones regionales de salud en provincias, sobre los tamizajes que se hicieron a los transeúntes que asistían a las estaciones de transporte público y los vendedores de los mercados en Lima y provincia mediante test rápidos de diagnósticos de detección de anticuerpos (prueba rápida) ${ }^{(4)}$. Se encontró un gran porcentaje de positividad en algunos mercados populosos (Tabla 1), como por ejemplo el Mercado de Frutas ubicado en el distrito de La Victoria y el Mercado de Belén en Iquitos, son mercados mayoristas con una elevada afluencia de público y positividad para COVID-19, esto quizás se deba a la elevada densidad poblacional de los distritos donde se encuentran los mercados y los hábitos de su población, por ejemplo, la cercanía de los puestos de venta, la informalidad.

\footnotetext{
${ }^{1}$ Universidad Nacional Pedro Ruiz Gallo. Lambayeque, Perú.

${ }^{2}$ Universidad Nacional de Jaén. Cajamarca, Perú.

a Biólogo, Facultad de Ciencias Biológicas

Sebastian Iglesias-Osores ORCID: https://orcid.org/0000-0002-4984-4656 Johnny Leandro Saavedra-Camacho ORCID: https://orcid.org/0000-0002-3842-4314 Lizbeth M Córdova-Rojas ORCID: https://orcid.org/0000-0002-9998-5019
} 
Tabla 1. Frecuencia de COVID-19 en comerciantes de diferentes mercados de abasto del Perú. 2020.

\begin{tabular}{|c|c|c|c|c|}
\hline Mercado & Región & $\mathbf{N}$ & COVID-19 Positivo (N) & COVID-19 Positivo (\%) \\
\hline Mercado de Belén & Loreto & 222 & 221 & 99,6 \\
\hline Mercado de Frutas & Lima & 164 & 147 & 89,6 \\
\hline Mercado Minorista Pucallpa & Ucayali & 175 & 114 & 65,1 \\
\hline Mercado Micaela Bastidas & Lima & 100 & 61 & 61,0 \\
\hline Mercado del Exterminal Pesquero & Piura & 383 & 230 & 60,1 \\
\hline Mercado 9 de octubre & Lambayeque & 100 & 59 & 590,0 \\
\hline Mercado Ciudad de Dios & Lima & 220 & 120 & 54,6 \\
\hline Mercado Plaza Villa Sur & Lima & 224 & 117 & 52,2 \\
\hline Mercado Las Capullanas & Piura & 200 & 102 & 51,0 \\
\hline Mercado Condevilla & Lima & 120 & 60 & 50,0 \\
\hline Mercados Central y Santa Lucía (Ferreñafe) & Lambayeque & 100 & 49 & 49,0 \\
\hline Mercado Conzac & Lima & 200 & 96 & 48,0 \\
\hline Mercado Unicachi & Lima & 165 & 78 & 47,3 \\
\hline Mercado Plaza del Mar & Piura & 163 & 74 & 45,4 \\
\hline Mercado El Ermitaño & Lima & 140 & 62 & 44,3 \\
\hline Mercado Minorista N. ${ }^{\circ} 1$ & Lima & 217 & 93 & 42,9 \\
\hline Mercado Surquillo & Lima & 631 & 261 & 41,4 \\
\hline Mercado La Hermelinda & La Libertad & 200 & 80 & 40,0 \\
\hline Mercado Modelo de Chiclayo & Lambayeque & 200 & 78 & 39,0 \\
\hline Mercado Huamantanga & Lima & 200 & 77 & 38,5 \\
\hline Mercado Rojo & Callao & 139 & 53 & 38,1 \\
\hline Mercado Mayorista de Jauja & Junín & 20 & 7 & 35,0 \\
\hline Mercado Modelo de Lambayeque & Lambayeque & 100 & 34 & 34,0 \\
\hline Mercado Anexo & Piura & 237 & 71 & 30,0 \\
\hline Mercado Dos de Mayo & Áncash & 245 & 61 & 24,9 \\
\hline Mercado Las Mercedes & Piura & 53 & 13 & 24,5 \\
\hline Mercado de Chongos Bajo & Junín & 30 & 7 & 23,3 \\
\hline Mercado Caquetá & Lima & 842 & 160 & 19,0 \\
\hline Mercado Moshoqueque & Lambayeque & 500 & 95 & 19,0 \\
\hline Mercado 3 de enero & Callao & 150 & 24 & 16,0 \\
\hline Mercado de Belén & Loreto & 222 & 221 & 99,55 \\
\hline Mercado 3 de enero & Callao & 150 & 24 & 16,0 \\
\hline
\end{tabular}

Fuente: Centro Nacional de Epidemiología, Prevención y Control de Enfermedades (CDC) de Perú. 
La prevalencia encontrada en los mercados es superior a muchos estudios similares llevados a cabo en otros sitios donde asiste público como los gimnasios ${ }^{(5)}$. La positividad encontrada en las estaciones de transporte público de Lima es también importante, ya que oscilan entre un 13,4 - 43,7 \% (Tabla 2), es preocupante por el diseño del transporte en donde los pasajeros van muchas veces a centímetros de distancia unos de otros; se conocen otros estudios en los que se habla sobre los riesgos de visitar estaciones de tren ${ }^{(6)}$.

Tabla 2. Frecuencia de COVID-19 en transeúntes de diferentes estaciones de transporte público de Lima- Perú. 2020

\begin{tabular}{|c|c|c|c|}
\hline Estación de transporte & $\mathrm{N}$ & COVID-19 Positivo (N) & COVID-19 Positivo (\%) \\
\hline Caja de Agua & 151 & 66 & 43,7 \\
\hline Gamarra & 150 & 38 & 25,3 \\
\hline Naranjal (Metropolitano) & 150 & 23 & 15,3 \\
\hline Matellini (Metropolitano) & 179 & 24 & 13,4 \\
\hline
\end{tabular}

Fuente: Centro Nacional de Epidemiología, Prevención y Control de Enfermedades (CDC) de Perú

Si bien es cierto que los pobladores usan mascarillas, medida obligatoria desde el inicio de la pandemia, existe la posibilidad de que estas personas puedan contagiar a otras en las aglomeraciones de los mercados y las estaciones de transporte. Si bien es cierto que las medidas han contribuido a disminuir la transmisión viral, aún existen varios puntos que no se han tomado en cuenta en el país ${ }^{(7)}$. Los mercados y estaciones de transporte público como el tren eléctrico o paraderos de buses han seguido abiertos para el uso de la población en medio de la cuarentena en Perú, promoviendo contagios masivos, esto en gran medida por los horarios restrictivos para realizar compras y la cantidad reducida de mercados. Otro factor social como la falta de refrigeradoras en los hogares peruanos ${ }^{(8)}$ ha generado el aumento de aglomeraciones en los mercados. El Gobierno ha fallado dando toque de queda o aislamiento obligatorio por 48 horas, creando así cuellos de botella, el objetivo del aislamiento social no es tener las calles vacías si no por lo contrario evitar el contagio. El Gobierno municipal y regional no ha dado planes de descentralización de mercados ni han abierto nuevas estaciones de transporte. No se encontró correlación estadística entre las regiones y la cantidad de casos positivos.

Se debería crear mercados satélites que estén abiertos muchas más horas que las permitidas por el toque de queda, dando así oportunidad a las personas de poder movilizarse sin aglomerarse, y descongestionando las horas punta. Se debe mejorar la ventilación en los buses y crear paraderos satélites, usar protectores faciales para viajar en el transporte público, aquí también se debería incrementar la flota de buses para aminorar los tiempos de espera en las estaciones.

Fuentes de financiamiento: Autofinanciado.

Conflictos de interés: Los autores declaran no tener conflictos de interés.

\section{REFERENCIAS BIBLIOGRÁFICAS}

1. Jang S, Han SH, Rhee J-Y. Cluster of Coronavirus Disease Associated with Fitness Dance Classes, South Korea. Emerg Infect Dis. 2020;26(8). doi:10.3201/eid2608.200633

2. Qu G, Li X, Hu L, Jiang G. An Imperative Need for Research on the Role of Environmental Factors in Transmission of Novel Coronavirus (COVID-19). Environ Sci Technol. 2020;54(7):3730-3732. doi:10.1021/acs.est.0c01102

3. $\mathrm{Xu} \mathrm{RH}, \mathrm{He} J \mathrm{~F}$, Evans MR, et al. Epidemiologic clues to SARS origin in China. Emerg Infect Dis. 2004;10(6):1030-1037. doi:10.3201/ eid1006.030852

4. Centro Nacional de Epidemiología Prevención y Control de enfermedades. Situación actual "COVID-19" al 29 de junio 2020. Lima; 2020. https://www.dge.gob.pe/portal/docs/tools/coronavirus/coronavirus160620.pdf. Accedido octubre 19, 2020.

5. Shim E, Tariq A, Choi W, Lee Y, Chowell G. Transmission potential and severity of COVID-19 in South Korea. Int J Infect Dis. 2020;93:339344. doi:10.1016/j.ijid.2020.03.031

6. Hu M, Lin H, Wang J, et al. Risk of Coronavirus Disease 2019 Transmission in Train Passengers: an Epidemiological and Modeling Study. Clin Infect Dis. julio 2020. doi:10.1093/cid/ciaa1057

7. Lyu W, Wehby GL. Community Use Of Face Masks And COVID-19: Evidence From A Natural Experiment Of State Mandates In The US. Health Aff. 2020;39(8):1419-1425. doi:10.1377/hlthaff.2020.00818

8. Instituto Nacional de Estadística e Informática (INEI). Perú - Encuesta Nacional de Hogares sobre Condiciones de Vida y Pobreza 2018; 2019. https://webinei.inei.gob.pe/anda inei/index.php/catalog/672/ related_materials. Accedido octubre 12, 2020. 